\title{
Safety climate strength: a promising construct for safety research and practice
}

\author{
Timothy J Vogus
}

Correspondence to Professor Timothy J Vogus, Owen Graduate School of Management, Vanderbilt University, 401 21st Avenue South, Nashville, TN 37203 USA; timothy.vogus@owen. vanderbilt.edu

Accepted 5 January 2016 Published Online First 25 January 2016

\section{SLinked}

http://dx.doi.org/10.1136/ bmjqs-2015-004150

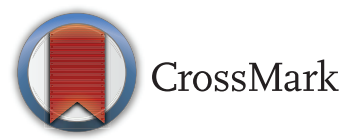

To cite: Vogus TJ. BMJ Qual Saf 2016;25:649-652.
Despite some notable advances in patient safety (eg, an average 17\% reduction across a set of hospital-acquired conditions including adverse drug events and urinary tract infections in the USA between 2010 and $2015^{1}$ ), substantially reducing or eliminating harm remains elusive for nearly every healthcare organisation. One consistent recommendation for becoming harm-free is developing a strong safety climate or shared employee perceptions that safety is organisationally rewarded, supported, valued and prioritised relative to other organisational goals. ${ }^{2}{ }^{3}$ Safety climate is closely related to safety culture in that the former represents perceptions of leader actions and organisational practices reflective of the underlying basic assumptions and beliefs comprising culture. ${ }^{4}$ Ginsburg and Oore, ${ }^{5}$ like much of the research in healthcare, focus on safety climate and its measurement through surveys.

There is growing empirical evidence in healthcare that safety climate matters to multiple indicators of safety including patient safety indicators, ${ }^{67}$ hospital readmissions $^{8}$ and treatment errors. ${ }^{4} 910$ More recently, studies suggest that a safety climate can serve as a resource to those delivering care, helping to reduce burnout. ${ }^{11} 12$ Consequently, there have been efforts by accreditors (eg, the Joint Commission in the USA) and advocacy organisations (eg, the Leapfrog Group) to encourage regular efforts to survey their employees regarding safety climate and benchmark those results/learn from the data. $^{13}$

The study from Ginsburg and Oore ${ }^{5}$ presents evocative findings suggesting that despite the importance of safety climate, our approach to assessing it is incomplete at best and misguided at worst. They helpfully illustrate that how we conceptualise and measure safety climate shapes our understanding of it and the resulting interventions we deploy often in ways that might be inimical to actually producing a strong safety climate. In other words, current approaches to measurement and interpretation paint, at times, an inaccurate picture of safety climate.

Specifically, the exclusive focus on the level of safety climate derived from survey measures for organisations (eg, a hospital, unit or clinic) that exhibit strong consensus (ie, pass a threshold level of within entity agreement) can be misleading. ${ }^{14}$ Focusing on consensus leads us to misrepresent or omit entities exhibiting disagreement about their safety climate. This can lead to biased findings and perhaps even excluding the entities in most need of interventions. Therefore, Ginsburg and Oore propose evaluating the 'safety profile' for each of the organisation surveyed that captures the level of safety climate, its 'strength' or the variability of safety climate perceptions among members and its 'shape' or an illustration of the spread of responses within a given organisation.

They argue that assessing climate strength provides insight into the consistency of behavioural expectations and actual safety behaviours in a work unit. ${ }^{15}$ The authors offer the SD as a simple measure of strength and the more sophisticated $\mathrm{rWG}(\mathrm{J})$ that they expertly detail in their technical appendix as an alternative. ${ }^{5}$ Strong climates are seen to enhance performance by energising employees around a meaningful, unified goal and shaping and coordinating employees' behaviour. ${ }^{15}$ Research also demonstrates that strong climates are more likely to persist and produce more consistent, uniform behaviour. ${ }^{16}$

They also encourage viewing the shape of by plotting a simple histogram of 
responses to see if there are clear subgroups within an organisation. In other words, does a safety climate level of 3 on a 1-5 scale mean clustering around three or half a unit's members rating a 1 and the other half a 5 ? Thus, a histogram of the pattern of responses can yield more diagnostic information regarding the safety climate.

\section{DO ORGANISATIONS HAVE A SINGLE SAFETY CLIMATE?}

Safety climate research typically views climate and culture as grounded in a relatively stable set of artefacts, values and basic assumptions that reflect the understandings that the members of a collective have arrived at over time and the practices and processes that result from them. ${ }^{17}{ }^{18}$ In other words, there is presumed to be organisation-wide consensus, consistency and clarity regarding culture and climate. ${ }^{15}$ Implicit in this depiction is the idea that people are relatively passive recipients of climate and culture. By refocusing us on the fact that a safety climate can be of low strength (ie, not shared), Ginsburg's and Oore's ${ }^{5}$ findings suggest that culture and climate may be more mutable, shaped by processes of mutual interaction and influence among organisational members carrying out their everyday work. ${ }^{19}$ Ginsburg's and Oore's methodological critique of safety climate is also fundamentally a conceptual critique echoed in many disciplines including political science and sociology that climate in general and safety climate in particular are rarely harmonious and integrated and more likely to be fraught with rivalry and conflict. ${ }^{17} 2021$ In other words, safety climate may be integrated and high strength, but it is just as likely that it is differentiated or fragmented. ${ }^{17}$

A differentiation perspective on climate identifies and examines inconsistencies in its manifestations in organisations. That is, the focus is the differences between consistent and coherent subclimates (eg, professions, departments, jobs, hierarchical levels, etc) that hold differing opinions of what should happen and why. ${ }^{17}$ Consequently, the differentiation view holds that climate change tends to be local and incremental.

A fragmentation approach to climate notes that organisational goals themselves are unclear and contested such that consensus is very difficult to achieve. Consequently, culture exists as a loosely structured and incompletely shared system that emerges dynamically as cultural members experience each other, events and the organisation's contextual features. ${ }^{17}$ Consensus is transient and issue-specific with persistent ambiguity rather than clarity at the core of culture.

A focus on safety climate strength and shape allows for directly exploring the differentiation and fragmentation perspectives on climate. Research on safety climate consistently finds differences in safety climate levels for different subgroups (eg, physicians vs nurses). For instance, in hospital ${ }^{22}$ and ambulatory ${ }^{23}$ settings, there are observed differences in hierarchical level, with leaders expressing more positive views of safety climate than physicians or other staff. That is, safety climate strength varies and the shape (eg, a bimodal distribution) is likely to be linked to specific subgroups. Identifying the specific subgroups disagreeing is an important first step to better interventions and greater coherence. For example, are the fault lines in the organisation based on hierarchical level (ie, leaders have an overly favourable perception) or profession (nurses have an unfavourable view of the safety climate)? For the former, putting leaders in closer contact with operational reality might be especially useful. In the latter, creating mechanisms for the frontline to speak up and demonstrating responsiveness to the concerns raised might be especially helpful. If the fault lines are demographic-age, education, ethnicity/race or gender-then a different set of interventions to bridge the divide(s) may be necessary. Building cultural competence to enhance crossboundary understanding may be especially effective. ${ }^{24}$ Examining the effects of these types of interventions on climate strength is a promising area for future research. In addition, the consequences of low climate strength for safety behaviours, organisational cohesion and safety and quality outcomes also merit exploration.

There is also some evidence to suggest that investigating safety climate strength and shape may find, consistent with the fragmentation perspective, that climate strength is transient and tied to specific issues. For example, Hickner et $a l^{23}$ find strong consensus regarding the organisational learning and overall perceptions of patient safety and quality components of safety climate in the ambulatory settings they studied. At the same time, there was little agreement for other aspects of safety climate (communication about error, staff training and teamwork ${ }^{23}$ ). These findings, coupled with Ginsburg Oore study, suggest that future research should explore safety climate strength as potentially variable across components. Similarly, the shape of the subcomponents of safety climate should be depicted to further focus intervention to improve safety climate.

Leaders are often the interpretive filters through which employees experience work-related events, practices and processes. Consequently, they can create greater consensus through their actions and approach to leadership. Transformational leaders who engage extensively in individualised interactions and otherwise work to foster higher quality communication among organisational members. By engaging behaviours consistent with transformational leadership, leaders increase organisational consensus around issues $^{25}$ and enhance safety climate strength in military organisations. ${ }^{26} 27$ Prior research in military 
brigades has also found that bottom-up processes such as team cohesion create consensus and greater safety climate strength. ${ }^{27}$ Thus, future studies should explore the role of transformational leadership and team cohesion in healthcare organisations on the level and strength of safety climate.

Exploring the full safety climate profile might also help to explain why there are inconsistent results for interventions like WalkRounds. ${ }^{28}$ Such interventions might be especially likely to improve safety climate, given their broad reach, on units that exhibit low strength safety climate scores. That is, strong, visible leadership support for safety (eg, WalkRounds) may improve the consensus regarding leader commitment to safety that is foundational to safety climate as well as the level of leader commitment demonstrated in prior research. ${ }^{28} 29$

In addition to leader style and behaviour, organisation size, ${ }^{23}$ structure (eg, physician-owned rather than university-owned) ${ }^{23}$ and practices are likely to influence safety climate strength. Organisational practices such as recruiting and selecting people for fit with the organisation's safety climate, investing in socialisation and training practices that convey the importance and priority of safety and build relationships among employees $^{15}$ may enhance safety climate strength. Recent work suggests that related organisational practices like hiring and training for interpersonal skills influence safety behaviours and improves patient safety outcomes. ${ }^{30}$

Making use of the differentiation and fragmentation perspectives on safety climate by studying safety climate strength helps explore climate variation more broadly. Specifically, it is possible that different facetspecific climates (eg, safety climate and production climate) may exhibit varying degrees of strength. In other words, it would make explicit the trade-offs being made throughout the organisation. Such information may be diagnostic in two ways-(1) if one form of climate is especially strong (production), it could provide learning for how to strengthen another (safety) and (2) it allows for the exploration of climate consensus across a broad set of norms and, in turn, a more accurate estimate of how much organisational climate consensus actually exists. ${ }^{31}$

Climate strength is also potentially consequential for those delivering care. A strong safety climate is an important coping resource for individuals committing errors and/or harm to a patient (ie, second victims ${ }^{11}$ ). When a climate's strength is weak, it may indicate that some individuals systematically lack access to such resources and are more likely to experience the negative consequences that befall second victims like emotional exhaustion, withdrawal and even substance abuse. ${ }^{11}{ }^{32}$ Therefore, future research should examine the range of effects of climate strength on individuals. More specifically, it would be useful to examine if safety climate strength moderates the relationship between being a second victim and deleterious outcomes like emotional exhaustion.

Ginsburg's and Oore's encouragement to examine safety climate data in a more nuanced manner provides an opportunity to broaden and deepen research on safety climate. Consistent with recent calls for reinvigorating quality and safety research with theory, ${ }^{33}$ it is now essential for researchers to more fully integrate research on safety climate with thinking on climate and culture in ways that reflects its conflict, dynamism and fragility. In other words, we need better theory to align with the better measurement that Ginsburg and Oore detail. Doing so can fruitfully direct research on transformational leader behaviours and organisational practices, especially selection and socialisation practices, as important antecedents of safety climate strength. Additionally attending to safety climate strength and shape can provide insights into who differs and why when climate strength is weak and fault lines are evident. Further increasing the sophistication of how we measure, represent and theorise safety climate enhances its utility for both theory and practice.

Competing interests None declared.

Provenance and peer review Commissioned; internally peer reviewed.

\section{REFERENCES}

1 Saving Lives and Saving Money: Hospital-Acquired Conditions Update. December 2015. Agency for Healthcare Research and Quality, Rockville, MD. http://www.ahrq.gov/professionals/ quality-patient-safety/pfp/interimhacrate2014.html

2 Weick KE. Organizational culture as a source of high-reliability. California Manage Rev 1987;29:112-27.

3 Weick KE, Sutcliffe KM. Managing the unexpected: resilient performance in and age of uncertainty. 2nd edn. San Francisco, CA: Jossey-Bass, 2007.

4 Singer SJ, Vogus TJ. Reducing hospital errors: Interventions that build safety culture. Annu Rev Public Health 2013;34:373-96.

5 Ginsburg L, Gilin Oore D. Patient safety climate strength: a concept that requires attention. BMJ Qual Saf 2016;25:680-7.

6 Singer S, Lin S, Falwell A, et al. Relationship of safety climate and safety performance in hospitals. Health Serv Res 2009;44 (Part I):399-421.

7 Mardon RE, Khanna K, Sorra J, et al. Exploring relationships between hospital patient safety culture and adverse events. J Patient Saf 2010;6:226-32.

8 Hansen L, Williams M, Singer S. Perceptions of hospital safety climate and incidence of readmission. Health Serv Res 2010;42:596-616.

9 Hofmann DA, Mark B. An investigation of the relationship between safety climate and medication errors as well as other nurse and patient outcomes. Personnel Psychol 2006;59:847-69.

10 Neal A, Griffin MA. A study of the lagged relationships among safety climate, safety motivation, safety behavior, and accidents at the individual and group levels. J Appl Psychol 2006;91:946-53. 
11 Profit J, Sharek PJ, Amspoker AB, et al. Burnout in the NICU setting and its relation to safety culture. BMJ Qual Saf 2014;23:806-13.

12 Sexton JB, Sharek PJ, Thomas EJ, et al. Exposure to leadership WalkRounds in neonatal intensive care units is associated with a better patient safety culture and less caregiver burnout. BMJ Qual Saf 2014;23:814-22.

13 Sorra J, Famolaro T, Dyer N, et al. Hospital Survey on Patient Safety Culture: 2012 User Comparative Database Report (Prepared by Westat, Rockville, MD, under contract No. HHSA 290200710024C). AHRQ Publication No. 12-0017. 2013.

14 Singer SJ, Vogus TJ. Safety climate research: taking stock and looking forward. BMJ Qual Saf 2013;22:1-4.

15 Chatman JA, Cha SE. Leading by leveraging culture. California Manage Rev 2003;45:20-34.

16 Schneider B, Salvaggio AN, Subirats M. Climate strength: a new direction for climate research. J Appl Psychol 2002;87:220-9.

17 Martin J. Organizational culture: mapping the Terrain. Thousand Oaks, CA: Sage, 2002.

18 Schein EH. Organizational culture and leadership. 3rd edn. San Francisco, CA: Jossey-Bass, 2004.

19 Westwood RI, Clegg S. The discourse of organisation studies: dissensus, politics and paradigms. In: Westwood RI, Clegg S, eds. Debating organisation: point-counterpoint in organisation studies. Oxford, UK: Blackwell, 2003:1-42.

20 Perrow C. The next catastrophe: reducing our vulnerabilities to natural, industrial, and terrorist disasters. Princeton, NJ: Princeton University Press, 2007.

21 Silbey SS. Taming prometheus: talk about safety culture. Ann Rev Soc 2009;35:341-69.

22 Singer SJ, Gaba DM, Geppert JJ, et al. The culture of safety: results of an organization-wide survey of 15 California hospitals. Qual Saf Health Care 2003;12:112-18.
23 Hickner J, Smith SA, Yount N, et al. Differing perceptions of safety culture across job roles in the ambulatory setting: analysis of the AHRQ Medical Office Survey on Patient Safety Culture. BMJ Qual Saf 2016;25:588-94.

24 Weech-Maldonado R, Elliott M, Pradhan R, et al. Can hospital cultural cometency reduce disparities in patient experiences with care? Med Care 2012;50(11, Suppl 3):S48-55.

25 González-Romá V, Peiró JM, Tordera N. An examination of the antecedents and moderator influences of climate strength. J Appl Psychol 2002;87:465-73.

26 Zohar D, Luria G. A multilevel model of safety climate: cross-level relationships between organization and group-level climates. J Appl Psychol 2005;90:616-28.

27 Luria G. Climate strength: how leaders form consensus. Leadership Q 2008;19:42-53.

28 Singer SJ, Tucker AL. The evolving literature on safety WalkRounds: emerging themes and practical messages. BMJ Qual Saf 2014;23:789-800.

29 Thomas EJ, Sexton JB, Neilands TB, et al. The effect of executive walk rounds on nurse safety climate attitudes: a randomized trial of clinical units. BMC Health Serv Res 2005;5:28-36.

30 Vogus TJ, Iacobucci D. Creating highly reliable health care: how reliability enhancing work practices affect patient safety in hospitals. ILR Rev. In Press.

31 Chatman JA, Caldwell DF, O'Reilly CA, et al. Parsing organizational culture: How the norm for adaptability influences the relationship between culture consensus and financial performance in high-technology firms. J Organiz Behav 2014;35:785-808.

32 Ullström S, Sachs MA, Hansson J, et al. Suffering in silence: a qualitative study of second victims of adverse events. BMJ Qual Saf 2014;23:325-31.

33 Davidoff F, Dixon-Woods M, Leviton L, et al. Demystifying theory and its use in improvement. BMJ Qual Saf $2015 ; 24: 228-38$. 